\title{
Por uma descolonização da América Latina
}

\author{
Por una descolonización en Latinoamérica \\ For a decolonization of Latin America
}

\author{
Bárbara Heliodora Andrade Ramos ${ }^{1}$
}

\begin{abstract}
Resumo
O presente artigo estabelece uma análise crítica do tema apresentado que tem presença constante nos meios midiáticos. Ele examina e discute a relação entre a diversidade cultural e a descolonização. O tema reveste-se de fundamental importância, por sua especificidade e também pelas diversas áreas do conhecimento que implica, visto tratar-se da interação entre os conteúdos, permitindo o diálogo e a troca de conhecimentos e experiências. Ao se pensar a temática, estabelece-se uma discussão útil aos pesquisadores que os habilita a reexaminar novas regras e práticas concernentes às concepções das políticas públicas.
\end{abstract}

Palavras-Chave: Descolonização, Diversidade Cultural, Identidade, Políticas Públicas.

\section{Resumen}

Este artículo presenta un análisis crítico del tema presentado que ha mostrado presencia constante en los medios de comunicación. Se examina y analiza la relación entre la diversidad cultural y la descolonización. El tema es de fundamental importancia por su especificidad, y también por las diferentes áreas de conocimiento que implica, dado que es la interacción entre los contenidos, lo que permite el diálogo y el intercambio de conocimientos y experiencias. Al pensar en el tema se establece una discusión útil para los investigadores que les permite reconsiderar las nuevas normas y prácticas en el diseño de políticas públicas.

Palabras claves: la descolonización, la diversidad cultural, la identidad, la política pública.

\section{Abstract}

This article establishes a critical analysis of the presented theme that has a constant presence in the media. It examines and discusses the relationship between cultural diversity and decolonization. The subject is of fundamental importance, due to its specificity and to the different areas of knowledge that it implies, since it is the interaction between the contents, allowing the dialogue and the exchange of knowledge and experiences. When thinking about the subject, a useful discussion established to the researchers that enables them to reexamine new rules and practices concerning the conceptions of public policies.

Keywords: Decolonization, Cultural Diversity, Identity, Public Policy.

\section{Introdução}

O desenvolvimento dos países latino-americanos voltou a ocupar papel privilegiado no debate social e econômico no início do século XXI, com impacto na agenda dos governos, na formulação de políticas públicas e na condução da política econômica. Após vinte anos de reduzido crescimento e elevado desemprego, os desequilíbrios estruturais e desigualdades econômicas e sociais foram agravados.

\footnotetext{
${ }^{1}$ Mestra pelo Programa de Pós-graduação em Administração (PPGAD) da Universidade Federal Fluminense/ UFF. E-mail. ramosbarbara07@gmail.com. Trabalho apresentado no I Seminário Latino-Americano de Estudos em Cultura - SEMLACult, Foz do Iguaçu/PR, Brasil, 2017.
} 
O debate político sobre o desenvolvimento dos países da América Latina está apontando para a recuperação de um tema obrigatório relacionado com um futuro mais próspero, distributivo, justo e inclusivo socialmente. Essa compreensão, partilhada por diversos autores e correntes, não é nova.

$\mathrm{Na}$ América Latina, vivemos em sociedades pós-coloniais, somos herdeiros de novas formas de colonialismo que são gerados no do próprio presente. A questão hoje para discutir está relacionada a descolonialidade de poder, tão ampla que dá grande liberdade para responder. Onde lacunas vem avançando com o desmantelamento da colonialidade do poder aberto, e como falar sobre eles? Qual o papel que as relações de poder neste processo e, especialmente no caso da cultura, que é o que hoje se encontram?

O trabalho está dividido em três seções, além desta introdução e das considerações finais. A primeira apresenta um percurso histórico da temática. A segunda examina os conceitos de cultura, identidade e diversidade cultural. A terceira repensa algumas práticas das políticas culturais de base comunitária e do Mercosul.

\section{PERCURSO HISTÓRICO}

O processo de industrialização, especialmente no Brasil, a partir de 1930 representou a emergência de um novo padrão de desenvolvimento, substituindo o modelo de desenvolvimento para fora, assentado na produção e exportação de bens primários. A industrialização latino-americana ocorreu necessariamente através da substituição de importações de bens industriais pela produção manufatureira interna. Seu avanço, no entanto, foi comprometido pela baixa capacidade de formação de poupança interna e de acumulação de capital e pela persistência do desequilíbrio de suas contas externas e de obstáculos estruturais internos.

Nos anos 1950 e 1960, pensadores de diversas formações dos países da região construíram um corpo teórico original e consistente voltado para a compreensão da dinâmica da realidade latino-americana, e a visualização dos caminhos necessários para viabilizar seu desenvolvimento. Suas concepções lançaram um olhar latino-americano sobre a América Latina, capaz de abranger sua realidade e propor alternativas para ultrapassar os obstáculos estruturais ao seu desenvolvimento.

Nesse contexto, os investimentos necessários para promover o desenvolvimento não foram suficientes para garantir seu dinamismo e sua sustentabilidade. O desenvolvimento 
latino-americano, pelo caminho obrigatório da industrialização substitutiva, não logrou eliminar seus profundos desequilíbrios estruturais, apesar da diversificação, modernização e maior eficiência de seu sistema econômico, e a melhora das condições sociais de sua população, devido à absorção produtiva de uma parcela considerável de sua força de trabalho.

A persistência dos obstáculos estruturais ao desenvolvimento da América Latina foi sempre preocupação dos pensadores Cepalinos. Visando sua superação, eles identificaram potenciais existentes nas sociedades latino-americanas e propuseram maior cooperação entre os países, seguindo um processo de integração regional direcionado para seu desenvolvimento. A superação dos obstáculos ao desenvolvimento requer uma opção política determinada, que rompa com a concentração do poder econômico. As relações do Brasil com seus vizinhos apresentam elementos paradoxais de uma integração notadamente assimétrica.

\section{APROXIMAÇÕES CONCEITUAIS}

Historicizar o conceito de cultura possibilita compreender sua transformação ao longo do tempo em suas dimensões antropológica e sociológica, segundo a ótica de autores de diferentes correntes.

A cultura permeia todas as ações da sociedade e, por consequência, todos os programas de governo. Cultura é comportamento; manifesta-se nas mínimas relações do cotidiano; é postura frente ao mundo. Exemplificando: a organização de um povo para a realização de atividades de interesse coletivo, como a criação de cooperativas, é cultura; a conformidade ou inconformidade com práticas sociais também podem ser manifestações de cultura; assim como o são todas as formas de resistência, o modo de encarar as adversidades, as lutas, individuais ou coletivas, tudo isto são fenômenos de natureza cultural.

É claro que qualquer definição ampla de cultura se apoia na perspectiva antropológica e considera a identidade dos grupos humanos e suas criações. Nas palavras de Lustosa da Costa (2006):

A cultura aqui é entendida em sentido amplo, contemplando toda herança não biológica que faz a diferença entre os povos; vale dizer, os diversos processos de designação e simbolização (linguagens), as inúmeras maneiras de lidar com a morte, o desconhecido e o imaginado (religiões e artes), as formas singulares de se relacionar com a natureza (tecnologias), as maneiras particulares de regular as relações sociais (instituições), inclusive, a produção e distribuição de bens (economia) e as diferenciadas formas de sociabilidade gratuita (festas, jogos e brincadeiras) e os julgamentos coletivos sobre o bom, o justo, o belo e o útil e o verdadeiro (ética, estética, pragmática e epistemológica). (LUSTOSA DA COSTA, 2006: 15) 
Para Williams (2011) ocorreu convergência prática entre o sentido antropológico e sociológico de cultura, por um lado, entendido como "modo de vida global" distinto, dentro do qual se desenvolveu um "sistema de significações", orientando a atividade social; por outro lado, o sentido mais especializado de cultura, com ênfase em um sistema de significação geral, com "atividades artísticas e intelectuais". A partir de então incorpora outras "práticas significativas", desde "a linguagem, passando pelas artes e filosofia, até o jornalismo, moda e publicidade", que constituem esse campo complexo e necessariamente extenso (WILLIAMS, 2011).

A ideia de Cultura como um recurso para a construção de identidades e para o desenvolvimento é um consenso forte o suficiente para sustentar, e tornar visíveis, narrativas sobre o campo cultural.

A cultura constitui uma dimensão fundamental do processo de desenvolvimento e contribui para fortalecer a independência, a soberania e a identidade das nações. De modo que alguns princípios devem reger as políticas culturais: a identidade cultural, a criação artística, intelectual, a educação artística, o patrimônio cultural, entre outros. Nesta afirmação percebese implicitamente que a diversidade cultural deve ser gerida no interior das sociedades e nenhuma cultura permanece isolada no mundo interdependente de hoje.

A identidade cultural contribui para a liberação dos povos; ao contrário, qualquer forma de dominação, a nega e deteriora. Como riqueza que dinamiza as possibilidades de realização, mobiliza, se renova e enriquece, compartilhando valores e tradições. Ao que tudo indica, identidade cultural e diversidade cultural são indissociáveis. (CAÑAL,1997)

O conceito de identidade tem sido muito discutido ao longo do tempo e, portanto, abriga diversas versões de cunho psicológico, filosófico, antropológico e sociológico. O Estado-Nação consolidou-se com a difusão de uma única cultura, gerenciada como modelo de identidade nacional. Atualmente convive com a fala reivindicatória daqueles grupos por ele silenciados. Eles exigem a reapropriação dos meios de definição de suas identidades. A globalização, através principalmente da compressão de distâncias e escalas temporais, tem contribuído para a contestação da centralidade das identidades nacionais.

Há, no entanto, um movimento de reforço destas e das identidades locais. Neste contexto de negociação surgem identidades culturais em transição, resultantes do diálogo 
entre diferentes tradições culturais do mundo globalizado: essas são as novas identidades ou identidades híbridas. (Hall, 2005).

Perceber a sociedade multicultural como a justaposição e convivência de etnias ou grupos em determinados espaços urbanos resulta em uma identidade construída socialmente e que desenha escolhas políticas de grupos humanos. (CANCLINI, 2004).

O conceito de identidade tem sido muito discutido ao longo do tempo e, portanto, abriga diversas versões de cunho psicológico, filosófico, antropológico ou sociológico. O EstadoNação consolidou-se com a difusão de uma única cultura gerenciada como modelo de identidade nacional. Atualmente convive com a fala reivindicatória daqueles grupos por ele silenciados. Eles exigem a reapropriação dos meios de definição de suas identidades. A globalização, através principalmente da compressão de distâncias e escalas temporais, tem contribuído para a contestação da centralidade das identidades nacionais.

A Declaração universal sobre diversidade cultural (2001) destaca a diversidade como patrimônio comum da humanidade; o pluralismo cultural apresenta-se como dimensão de reconhecimento da diversidade, visto que compreende respostas políticas que possibilitam "a inclusão e a participação de todos os cidadãos [e] garantem a coesão social, a vitalidade da sociedade civil e a paz" (art. 2).

A diversidade cultural seria fonte de desenvolvimento porque entendida não somente como crescimento econômico, mas também como meio de acesso à existência intelectual, afetiva, moral e espiritual satisfatória. O documento destaca a questão dos "bens e serviços culturais", esses pensados como mercadorias distintas de outras, uma vez que seriam portadoras de identidade, valores e sentido.

Do ponto de vista histórico, as diferenças entre identidade, diversidade e desigualdade estão intimamente ligadas. Por quê? Permite entender o papel da América Latina no contexto dos blocos econômicos de poder e analisar o processo de integração regional mostra o conjunto de ações que se refletem na dinâmica da sociedade e na reorganização dos territórios nacionais e regionais.

No Brasil diversos autores buscaram compreender o papel do elemento estrangeiro no processo histórico nacional (tanto no geral quanto em momentos específicos), como Caio Prado Júnior, Celso Furtado, Nelson Werneck Sodré, Florestan Fernandes, Theotonio dos Santos, entre outros. Caio Prado Júnior, através do que chamou de "Sentido da Colonização", 
focaliza o desenvolvimento histórico brasileiro como subserviente aos interesses externos, mas foi na chamada "Teoria da Dependência" que, através de Theotonio dos Santos, a análise dessa relação atingiu uma formulação mais ampla. Na justa compreensão da relação de dependência entre o Brasil e os centros econômicos mundiais está a chave para o entendimento das insuficiências nas rupturas de nossa história.

O debate por uma descolonização na América Latina tem ocupado importante espaço na agenda internacional, nos congressos e seminários de discussão e nas diversas publicações especializadas. No contexto contemporâneo de transformação do Estado e da sociedade, é uma verdade, mas isto não significa nenhuma novidade. Também é certo que o debate sobre a temática se confunde, na maior parte dos casos. Alguns estudiosos argumentam que as mudanças nas formas de regime político do Estado acontecem num ritmo mais acelerado do que as mudanças nas formas de política e gestão.

Também não se pode desconsiderar outro tema emergente, que é por uma relação entre a diversidade cultural e a descolonização, ainda que com mais perguntas do que respostas. $\mathrm{O}$ próprio campo de investigação se alargou, com a emergência, que deslocou o foco de investigação para inúmeros objetos antes colocados ao largo do interesse da pesquisa científica. Na América Latina, a diversidade cultural foi historicamente colocada em segundo plano de forma que as propostas de descolonização e outras transformações históricas conduziriam a uma soberania a um desenvolvimento da vida cultural no contexto nacional e internacional.

\section{O PAPEL DA UNESCO}

A UNESCO, criada em Paris (1946) é formada por Estados-membros e membros associados, e tem o objetivo de contribuir para a paz e a segurança no mundo, mediante o diálogo intercultural na educação, na ciência, na cultura e nas comunicações.

A UNESCO, no Brasil, foi estabelecida em 1964, com sede em Brasília e somente iniciou suas as atividades em 1972, tendo como prioridades a defesa de uma educação de qualidade para todos e a promoção do desenvolvimento humano e social. Desenvolve projetos de cooperação técnica em parceria com o governo-União, Estados e Municípios; a Sociedade civil e a iniciativa privada, além de auxiliar na formulação de políticas públicas que estejam em sintonia com as metas acordadas entre os Estados Membros da Organização. 
A formação dos blocos econômicos de poder se constitui de estratégias políticoeconômico-institucionais de determinados países, no sentido de tentarem fortalecer-se frente à lógica de (re)produção do capitalismo contemporâneo, em uma escala espaço-temporalmente desigual. Diante disso analisaremos o papel da UNESCO no cenário econômico regional, buscando entender como os países da América Latina se inserem nesse processo dinâmico.

Há um relativo consenso sobre as mudanças ocorridas na América Latina. Procura-se, em primeiro lugar, entender como a UNESCO "naturalizou" conceitos e suscitou novos temas e enfoques em pesquisas nas áreas de Ciências Sociais. Diversidade, pluralismo e direitos culturais, multiculturalismo, políticas culturais, identidades locais, gestão cultural, bens e serviços culturais, entre outros, apresentam-se na atualidade como uma espécie de força material, no sentido de orientar entendimentos e propor "soluções" para conflitos e tensões políticas, étnicas e sociais. Temas que não eram relacionados à cultura, na abordagem clássica das Ciências Sociais, passaram a sê-lo, a exemplo de cultura e economia, cultura e desenvolvimento sustentável, cultura e combate às desigualdades sociais, cultura e direitos culturais.

O desenvolvimento de um país está essencialmente ligado às oportunidades que ele oferece à população de fazer escolhas e exercer sua cidadania. E isso inclui não apenas a garantia dos direitos sociais básicos, como saúde e educação, como também segurança, liberdade, habitação e cultura.

Armatya Sen (2000) construiu sua visão alternativa apoiado na convicção de que a promoção do bem-estar (o que se quer afinal com o desenvolvimento) deve orientar-se por uma resposta adequada à pergunta ética por excelência: onde está o valor próprio da vida humana? $\mathrm{Na}$ vida de qualquer pessoa, certas coisas são valiosas por si mesmas, como, por exemplo, estar livre de doenças evitáveis, escapar da morte prematura, estar bem alimentado, ser capaz de agir como membro de uma comunidade, agir livremente e não ser dominado pelas circunstâncias, ter oportunidade para desenvolver suas potencialidades.

Para a Unesco colocar a cultura no centro das políticas de desenvolvimento sustentável constitui um investimento essencial ao futuro do mundo e é uma pré-condição para processos de globalização bem-sucedidos que levem em consideração o princípio da diversidade cultural. É imperativo integrar sistematicamente as especificidades culturais na concepção, na medida e na prática do desenvolvimento, já que isso garante o envolvimento de populações locais e o resultado satisfatório dos esforços para se atingir o desenvolvimento. 
A educação, as cidades sustentáveis, a segurança alimentar, o meio ambiente equilibrado, o crescimento econômico, os padrões sustentáveis de produção e consumo, bem como as sociedades pacíficas e inclusivas, como elementos relacionados aos Objetivos de Desenvolvimento Sustentável (ODS) afiguram-se essenciais para atender não apenas à solicitação da Assembleia Geral da ONU e aos órgãos administrativos da UNESCO, mas também à demanda dos Estados-membros em escala nacional.

Para os fins deste trabalho deve-se perceber que as noções de soberania, austeridade e territorialidade são como elementos marcantes entre as nações. É importante destacar que a consolidação de um sistema de cooperação e integração econômica entre países da América Latina enfrenta diversos obstáculos, os quais se fazem notar ainda hoje. De modo que se destaca uma política de comércio comum, bem como uma política agrícola comum; promoção do bem-estar socioeconômico; política comum no setor de infraestrutura, como energia, transporte e telecomunicações; livre circulação de pessoas, mercadorias, serviços e capitais.

Vale evidenciar que há divergências e fortes desigualdades entre os países da América Latina pois nem todos apresentam o mesmo nível de desenvolvimento e/ou a mesma força política e econômica. Pelo contrário, há países em situação socioeconômica de acentuada fragilidade. Os níveis regionais de pobreza e de indigência diferenciam-se, visto que são as áreas que apresentam maior gravidade e complexidade. Tais áreas, comparadas ao Brasil e à Argentina, evidenciam maior dependência, sobretudo econômica e tecnológica.

Para Ianni "as corporações transnacionais desempenham um papel básico, que pode ser decisivo na criação, institucionalização e dinamização dos sistemas econômicos regionais" (IANNI, 1996, p. 134). Elas correspondem, em força econômica, a um conjunto de países integrados, o que aumenta sua força e representatividade, pois suas influências têm um maior alcance espacial, de modo que seus interesses serão mais facilmente garantidos, ampliando seu mercado consumidor e sua produção.

Harvey (1999) afirma que “os novos métodos de trabalho são inseparáveis de um modo específico de viver e de pensar e sentir a vida". (HARVEY,1999, p. 121). Assim, as transformações tecnológicas em grande expansão promovem mudanças no mundo do trabalho, do consumo, no sistema econômico, nas estruturas econômicas e políticas dos países que detêm maiores níveis de riqueza. Atendem assim à lógica neoliberal de produção e acumulação de riqueza. 
Neste sentido a interligação global do sistema econômico, isto é, componentes como: os mercados financeiros, o comércio internacional, produção transnacional, ciência e tecnologia a economia global pode ser entendida, na visão CASTELLS (2007), como "uma economia cujos componentes centrais têm a capacidade institucional, organizacional e tecnológica de trabalhar em unidade e em tempo real, ou em tempo escolhido, em escala planetária" (CASTELLS, 2007, p. 143.)

Os conflitos territoriais historicamente são negligenciados e se apresentam de modo especial nas questões ambientais, étnicas, culturais, de violência, tráfico de pessoas, de mercadorias e de drogas, etc., a exemplo dos sucessivos e frequentes eventos que ocorrem na fronteira do Brasil com os países limítrofes. Problemas relacionados a essas e outras questões socioambientais ainda presentes nos países "integrados". Normalmente desconsidera-se ou pouco se atenta para a complexa questão das fronteiras nacionais, para os recursos e os interesses em jogo.

Por causa das desigualdades socioespaciais e regionais, e do processo de integração econômica, no contexto do MERCOSUL, o Brasil e a Argentina se constituem em países de forte convergência de imigrantes. Por exemplo, só em São Paulo (maior metrópole regional) estima-se que vivem cerca de 100 mil imigrantes bolivianos, boa parte destes submetida a condições de trabalho análogas ao trabalho escravo. Somam-se a esses, milhares de imigrantes peruanos, colombianos, venezuelanos, equatorianos, etc., todos praticamente submetidos a uma mesma lógica de expropriação e exploração do trabalho, bem como vivendo nas mesmas condições de vida, isto é, sujeitos a precárias condições alimentares, de moradia, de saúde, de educação e segurança.

\section{REPENSANDO ALGUMAS PRÁTICAS}

\section{BASE COMUNITÁRIA}

A participação dos cidadãos na cultura dentro de um novo paradigma de construção social, requer a presença de gestores culturais. Para gerir a cultura primeiro deve-se articular a Política Cultural e a Gestão Cultural em si. Isso seria um bom começo para um projeto de grandes ambições.

Em junho de 2015, em Santiago do Chile, aconteceu a $2^{\text {a }}$ Reunião do Comitê Intergovernamental do Programa Ibercultura Viva. Participaram da atividade representantes de oito países membros do Comitê, tais como: Argentina, Brasil, Chile, Costa Rica, El 
Salvador, Espanha, México e Peru. O objetivo foi debater as ações estratégicas do programa que visa a fortalecer o desenvolvimento de políticas culturais de base comunitária.

É relevante saber que este programa foi criado em 2014, com base na Declaração do II Congresso Iberoamericano de Cultura (São Paulo, 2009) e no Programa de Ação da XXIII Cúpula Iberoamericana de Chefes de Estado e de Governo (Cidade do Panamá, 2013), e sob as diretrizes da Secretaria Geral Iberoamericana. O Comitê Intergovernamental é formado por representantes da Argentina, do Brasil, do Chile, da Costa Rica, El Salvador, da Espanha, do México, do Paraguai, do Peru e do Uruguai.

Entre os objetivos do programa estão fomentar uma Rede Iberoamericana de Pontos de Cultura, promover intercâmbio de participantes da Política Nacional de Cultura Viva com os de políticas públicas equivalentes nos países iberoamericanos, capacitar gestores públicos para trabalhar com políticas culturais de base comunitária, fortalecer a Rede de Gestores Culturais nos países membros, definir uma legislação específica de políticas públicas em benefício das expressões culturais comunitárias e apoiar a produção e circulação de conteúdos culturais.

Com o propósito de atender à premissa do desenvolvimento de políticas culturais de base comunitária, o Ministério da Cultura do Brasil esteve presente no evento, no qual apresentou diretrizes da Política Nacional de Cultura Viva. A reunião foi fundamental para estreitar relações de cooperação entre os governos e entre movimentos sociais de cultura.

De certa forma acreditou-se que o Brasil poderia aprofundar os conceitos adotados nos Pontos de Cultura, uma referência em política cultural para vários países da América Latina. O Brasil preside o programa. Os países presentes demonstraram grande interesse pela Lei Cultura Viva, resultado de um intenso processo de escuta e participação social.

Por fim, a $2^{\mathrm{a}}$ Reunião do Comitê Intergovernamental do Programa Ibercultura Viva aprovou um plano de trabalho para os próximos dois anos, que inclui o lançamento de editais de intercâmbio e a participação de Pontos de Cultura Brasileiros e de outros países iberoamericanos no II Congresso Latinoamericano de Cultura Viva Comunitária, previsto para acontecer no México em 2017.

Roberto Guerra Veas (2015) esclarece que: 
fortalezas, en síntesis, la identidad. Aquello que funda y explica. Dicho conocimiento debe ser el punto de partida de los procesos de planificación del desarrollo cultural en nuestras comunidades. Como plantea Jesús Martín Barbero, se requieren políticas culturales que tengan en cuenta la memoria, y "las transformaciones de la identidad de los ciudadanos que habitan los barrios donde hacemos intervenciones urbanas". Desde esta perspectiva, no es posible una política cultural que no de cuenta de los mapas de las transformaciones de la identidad de los territórios. (GUERRA VEAS, 2015, 11)

Decorrem dessa leitura alguns esclarecimentos sobre as dificuldades encontradas, suas experiências, utopias, sonhos e dores. Acredita-se que a participação cidadã elabora sobre o que foi feito na gestão cultural da comunidade, além de consolidar diálogos com a sociedade civil no Chile.

\section{INTEGRAÇÃO CULTURAL DO MERCOSUL.}

Em conformidade com os documentos do MERCOSUL, a cultura tem uma responsabilidade que ultrapassa a erudição ou o simples rigor técnico da conexão com as formas e os significados que eram válidos na América do Sul de séculos atrás.

Como propõe Rodrigo Valverde (2012), há no MERCOSUL:

Por sua pretensão territorial, a cultura promovida nos documentos do MERCOSUL deve ser capaz de gerar atividades econômicas, de promover coordenações políticas e sugerir novas formas e comportamentos sociais para a região. Somente assim seria possível ao mesmo tempo promover o desenvolvimento econômico e territorial local, valorizar representações do passado, lidar com os rigores do mundo contemporâneo e criar novas representações que reforcem em plano produtivo e ideológico a integração do Bloco. (VALVERDE, 2012, p.8)

O MERCOSUL indica uma consolidação "na redução das barreiras alfandegárias" e ainda reforça a "responsabilidade de gestão e de produção cultural" por parte do Bloco. Não se trataria então apenas do reconhecimento da diversidade das culturas geridas e pensadas nacionalmente, mas de uma ampliação deste universo para contemplar a coprodução cultural com interferências de agentes supranacionais e locais.

Tal qual o texto apresenta, seria preciso, entre outras ações, promover diretamente a criação de espaços culturais e de eventos de intercâmbio, o que registra uma mudança em relação a um momento do final do século $\mathrm{XX}$ no qual o Estado e os poderes públicos pareciam unicamente se colocar como financiadores ou como agentes passivos diante da discussão da cultura. 


\section{CONSIDERAÇÕES FINAIS}

A ideia de Cultura como um recurso para a construção de identidades e o desenvolvimento é um consenso forte o suficiente para sustentar, e tornar visíveis, narrativas sobre o campo cultural.

As ideias aqui definidas proporcionam a esta investigação importante campo de estudo para análise dos elementos necessários. De outro modo, a visão inclusiva e conciliadora das políticas públicas, através de uma organização da sociedade civil, parece que coordena um projeto, promove a participação de especialistas em vários campos disciplinares. A metodologia adotada em projetos deve intervir em um determinado contexto, deve ser considerada no exercício de processos participativos, tornando clara a sua utilidade e relevância.

O tema da descolonização e das estratégias de integração na América Latina permite a ampliar e reexaminar novas regras e práticas concernentes às concepções de políticas públicas. Os limites e as possibilidades não se esgotam nem substituem outras alternativas para uma perspectiva crítica de análise.

\section{Referências}

CAÑAL, Carlos Yanez. Identidad, Aproximaciones al concepto. Revista Colombiana de Sociologia, Nueva serie, vol.III. N. 2, Colômbia, 1997

CANCLINI, Nestor. Diferentes, Desiguales y Desconectados: Mapas de La Interculturalidad. Ed. Gedisa, Barcelona: 2004.

CASTELLS,Manuel. A Galáxia Internet: Reflexões sobre internet, negócios e sociedade. Ed. Fundação Calouste Gulbenkian, Lisboa, 2007.

FURTADO, Celso. A Economia Latino-Americana. Ed. Companhia das Letras, São Paulo 2007.

FERNANDES, Florestan. Capitalismo Dependente e Classes Sociais na América Latina. Ed.Zahar, Rio de Janeiro, 1981.

GUERRA VEAS, Roberto. Gestión Cultural, Municipio y Participación Ciudadana. Apuntes Desde La Experiencia. Ponencia presentada en el Segundo Encuentro Nacional de Gestión Cultural realizado en San Pedro Tlaquepaque, Jalisco, México entre los días 15 al 17 de octubre de 2015.

Gestión y Autogestión em la Cultural y otros escritos. Ediciones Egac, Santiago de Chile, 2016. 
HALL, Stuart. Identidade Cultural na pós-modernidade. Ed. DP\&A, São Paulo, 2005.

HARVEY, David. Condição Pós-moderna. Ed.Loyola, São Paulo, 1999.

IANNI, Octavio. A Era do Globalismo. Ed.Civilização Brasileira Rio de Janeiro, 1996.

LUSTOSA DA COSTA, Frederico. Política e gestão cultural: Perspectivas Brasil e França. EDUFBA. Salvador.2013.

Bacia cultural do Araripe: articulando cultura, desenvolvimento sustentável e governança local. In: Reunião Anual da Associação Brasileira de Antropologia (ABA), 25, 11-14 jun. 2006. Anais... Goiânia, 2006.

PRADO JR., Caio. História Econômica do Brasil. Ed.Brasiliense, São Paulo, 1998.

SANTOS, Theotonio dos. A Estrutura da Dependência. Ed.American Economic Review, Rio de Janeiro, 1970.

SEN, Amartya. Desenvolvimento com Liberdade. Ed.Companhia das Letras, São Paulo, 2000 .

UNESCO. Declaração universal sobre diversidade cultural. 2001. Disponível em http://unesdoc.unesco.org. Acesso em 6/11/2016.

VALVERDE, Rodrigo R. H. F. Os itinerários do MERCOSUL Cultural: dilemas para a territorialização das Missões Jesuíticas-Guaranis. Cadernos PROLAM/USP, Ano 11, Vol. 2, 2012.

WILliAMS, Raymond. Cultura e Sociedade: de Coleridge a Orwell. Ed. Vozes. Petrópolis, 2011. 